\title{
Canakinumab in the routinary clinical practice in cryopyrin-associated periodic syndromes (CAPS): one year of follow-up
}

\author{
R Caorsi ${ }^{1 *}$, L Lepore $^{2}$, F Zulian ${ }^{3}$, M Alessio ${ }^{4}$, A Stabile $^{5}$, M Finetti $^{1}$, A Martini $^{1}$, M Gattorno $^{1}$ \\ From 18th Pediatric Rheumatology European Society (PReS) Congress \\ Bruges, Belgium. 14-18 September 2011
}

\section{Background}

No clear information on the optimal dosage of Canakinumab in CAPS is available.

\section{Aim}

To analyse the modification of dosage schedule of Canakinumab in CAPS in 12 months of routinely clinical practice.

\section{Methods}

12 patients ( 9 children and 3 adults) with Muckle-Wells syndrome (3), MWS/CINCA overlap (3) and CINCA (6) were analyzed. Patients were previously enrolled in the CACZ885D2306 trial and studied for the following 12 months.

\section{Results}

At baseline, 7 patients were treated with the initial dosage of $2 \mathrm{mg} / \mathrm{kg}$ (or $150 \mathrm{mg}$, if $>40 \mathrm{Kg}$ ) every 8 weeks. In 5 patients ( $2 \mathrm{MWS} / \mathrm{CINCA}$ overlap, 5 CINCA) the dosage was $4 \mathrm{mg} / \mathrm{kg}$ (or $300 \mathrm{mg}$ ) every 8 weeks.

During the following 12 months modification of dosage of frequency was performed in 7/12 patients. The 5 patients at higher dosage during the CACZ885D2306 study needed to increase the frequency of administration with a mean frequency of 6 weeks (range 4-8). The mean reason was the presence of mild clinical manifestation and/or persistent elevation of acute phase reactants. In one of these patients the therapy was subsequently discontinued due to persistent disease activity. An increased frequency (6 and 7 weeks) was also performed in 1 MWS and 1 CINCA patient, respectively.

In 5 patients the treatment was not modified being effective in the control of the disease.

\section{Conclusions}

This study confirms the efficacy of Canakinumab in CAPS. However, pediatric patients and those with a more severe phenotype require higher and more frequent dosage than previously described.

\section{Author details \\ 'UO Pediatria II, G. Gaslini Institute and Department of Pediatrics, University of Genoa, Genova, Italy. ${ }^{2}$ RCCS Burlo Garofalo, Dipartimento di Pediatria, University of Trieste, Trieste, Italy. ${ }^{3}$ Dipartimento A.I. di Pediatria, University of Padua, Padova, Italy. ${ }^{4}$ Department of Pediatrics, Federico II Hospital, Napoli, Italy. ${ }^{5}$ Department of Paediatrics, A. Gemelli Hospital, University of Rome, Italy.}

Published: 14 September 2011

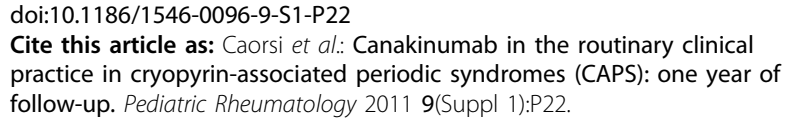

Cite this article as: Caorsi et al:: Canakinumab in the routinary clinical practice in cryopyrin-associated periodic syndromes (CAPS): one year of follow-up. Pediatric Rheumatology 2011 9(Suppl 1):P22. 